\title{
Much Ado about Something: Cuban Biotech
}

Cuban advances in biotech have made headlines, particularly since the US-Cuba rapprochement and signing of the historic memorandum of understanding between the US Department of Health and Human Services and Cuba's Ministry of Public Health in June. Some 34 Cuban institutions with 22,000 employees are the backbone of a biotech industry that dates to the early 1980s, obtaining novel products that have sparked interest among potential global partners. While a number of these Cuban products are registered in various countries, their testing in the USA remains ensnared in the red tape of embargo laws that tend to make investors skittish and thus delay, if not curtail, joint research and clinical trial applications to the FDA.

Nevertheless, Cuban researchers and their colleagues continue to exchange experiences in biotech, by far the fastest-growing sector of the pharma industry worldwide. For the first time, a robust delegation of Cuban scientists attended the BIO conference held earlier this year in San Francisco, which drew some 16,000 participants from the world over. There, Dr Agustín Lage, Director of Cuba's Molecular Immunology Center, presented aspects distinguishing Cuba's approach to biotech including the "closed-loop" strategy, which integrates research, industrial development and public health to make biotech a major driver of Cuba's economy. On a related note: congratulations are in order for Dr Lage, a contributor to MEDICC Review, for his designation by the Americas Quarterly as one of Latin America's Top Five Academics.[1]

Biotech innovation is also a key component of Cuba's ability to adopt universal health in a resource-scarce environment, as explained in this issue's Interview with Cristian Morales, PAHO-WHO Representative in Cuba. Dr Morales played a key role in advancing the milestone resolution adopted by PAHO's Directing Council, which commits all the region's governments to adopt action plans to pursue universal health access and coverage.

An article related to Cuba's own regulatory process for biotech and other pharmaceuticals heads this issue's Editors' Choice articles: a feature by Senior Editor Gorry reviewing the Cuban experience and challenges in establishing protocols and implementing clinical trials in the country's unified health system. She also touches on the role of the WHO-accredited Cuban Public Registry of Clinical Trials in Havana.

In another of our picks, Cruz-Hernández's Perspective places Cuba's policy and practice on detection of gestational diabetes in the context of evolving international debates. Gestational diabetes, which confers serious health risks on both mothers and children, is asymptomatic, making effective detection strategies critically important. Our third Editors' Choice is Beatriz Corona-Miranda's article analyzing Cuban suicide rates over almost three decades. While these show considerable decline, her research also calls attention to older-adolescent vulnerabilities. Suicide is the third cause of death in Cubans aged 10-19 years, after unintentional injuries (principally motor vehicle accidents) and cancer.[2] The group aged 15-19 years constitutes only $27 \%$ of Cuban children and youth aged $<20$ years, but accounts for $88 \%$ of suicide burden among them.

Also focusing on youth, Fabelo-Roche's Lessons from the Field reports on intersectoral action to delay youth drinking, a topic of particular concern due to the lifelong health and social consequences of early alcohol addiction. In a related Perspective, GonzálezMenéndez calls for stronger action to counter cultural and media influences that reinforce alcohol use as a socially accepted norm. Both articles illustrate that the health sector alone cannot effectively tackle the dangers of substance abuse and addiction.

In his Viewpoint, architect Miguel Coyula ponders the virtual disappearance of bicycles on Havana's urban landscape. He analyzes why most Cubans view cycling as transport of last resort, rather than healthy exercise or environmentally sound practice. He calls on government planning to generate a broad vision making bike riding not only affordable and safe, but also a pastime and preferred choice for a capital city in need of healthy transportation alternatives.

Since our last issue, MEDICC colleagues have suffered two tragic losses. One was the death, at 87, of Dr Ernesto de la Torre Montejo, founding Director of Cuba's Hematology Institute, and emeritus co-chair of MEDICC's Joint Academic Council and member of MEDICC Review's Editorial Board. Dr de la Torre studied medicine in Havana and specialized in pediatrics at Chicago's Cook County Hospital, where he also began work in hematology. Returning to Cuba, he was one of the young leaders who built the country's universal health system. He was a pioneer in many scientific endeavors, including US-Cuba cooperation in health, and applied his brilliance, modesty, good humor and natural gift as a teacher to each of them.

Our second loss was the death of Dr Pedro López Saura, a brilliant immunologist who collaborated with MEDICC Review for many years, first as a valued peer reviewer and later as issue coordinator. We are fortunate to have had the privilege of working with him. Dr López Saura was the youngest member of the team tapped to launch Cuba's biotech industry in the early 1980s, the group that produced the first Cuban interferon. He later went on to become a professor and lead researcher at the Genetic Engineering and Biotechnology Center, where his latest work concerned Heberprot-P, the diabetic foot ulcer medication approved in Cuba and elsewhere, initial studies indicating it reduces relative amputation risk by $70 \%$.

The staff of MEDICC and MEDICC Review extend heartfelt condolences to the families and friends of these two great figures in Cuban medicine and public health. $-1 /$ -

\section{The Editors}

An essential PS Dr Sarah Hernandez of Sacramento, California appears on our cover. This July, she received her degree from Havana's Latin American Medical School (ELAM), one of 11 US graduates, among the over 200 who have thus far received full Cuban scholarships for medical studies. She plans to return to the US to apply for a residency and to practice in primary health care, a path chosen by the vast majority of US ELAM graduates.

1. Tuminno A. AQ Top 5 Latin American Academics: Agustín Lage. Americas Quarterly. Available at: http://americasquarterly.org/content/aq-top-5-latin -american-academics-agustin-lage 